\title{
TERRITORIO Y PODER: YUCATÁN ENTRE LOS ULTIMOS AÑOS DEL POSTCLÁSICO Y LA PRIMERA EDAD COLONIAL
}

\section{TERRITORY AND POWER: YUCATAN BETWEEN THE LAST YEARS OF POSTCLASSIC AND THE FIRST COLONIAL AGE}

\author{
Gaia Carosi ${ }^{1}$
}

\section{RESUMEN}

Este artículo consiste en un análisis de los procesos territoriales que ocurrieron en la península de Yucatán a partir de la llegada de los conquistadores hispanos, lo anterior en base a un análisis de los procesos territoriales y una relectura de los primeros documentos coloniales en conjunto con la implementación de un sistema de información geográfica (SIG). La conquista no sólo implicó un cambio radical desde el punto de vista político, sino que la misma idea de poder cambió, pasando de ser de tipo personal a territorial: la distribución de la población y de los pueblos sobre la península tuvieron que adaptarse a la mentalidad importada por los europeos y a sus nuevas necesidades. Quienes detentaban el poder político sintieron la necesidad de definir claramente sus fronteras y los límites de sus dominios para adaptarse al cambio de mentalidad; con la modificación del sistema administrativo, los fulcros del poder sobre el territorio mutaron, mientras que las antiguas capitales perdieron su poder político. La congregación reunía a la población de aldeas y pequeños poblados en sitios seleccionados y muchas ciudades desaparecieron, reunidas dentro de otras, revolucionando al final la modalidad de asentamiento en el territorio, en una situación tumultuosa y en constante cambio.

Palabras clave: Yucatán; territorio; conquista; españoles; organización

\section{ABSTRACT}

Through a re-reading of the early colonial documents aided by the use of a Geographic Information System or GIS, we propose an analysis of the territorial processes occurred in Yucatan after the spanish conquest. The conquest didn't involve only a great political change: the very idea of political power changed, passing from a personal to a territorial one. The distribution of population and pueblos on the ground had to adapt to the mentality imported by europeans and to their new needs. Some potentates now defined clearly their borders and their territory in order to adapt to the mental change; the fulcrums of power related to territory mutated, while the ancient capitals lose their power. The population of many villages was united in selected sites by the congregación, and many cities disappeared, gathered within others, totally changing the way of settling on the space, in a tumultuous and constantly changing situation.

Keywords: Yucatan; territory; spanish; conquer; organization

Tipología: Artículo de reflexión

Fecha de recepción: 20/04/2016

Fecha de aceptación: 01/08/2016

Como citar este artículo: Carosi, G. (2016). Territorio y poder: Yucatán entre los últimos años del Postclásico y la primera edad colonial. Jangwa Pana, 15 (2), 251- 263

1. Doctoranda. Departamento de estudios clásicos. Universidad de Roma La Sapienza. Italia. Correo electrónico: gaia.carosi@uniroma1.it. ORCID ID: 0000-0001-9827-0858 


\section{INTRODUCIÓN}

$E^{1}$ objetivo de este trabajo es comprender los factores que influyeron en la disposición de los asentamientos mayas prehispánicos y observar el desarrollo de la situación y los cambios después de la conquista. Se decidió estudiar a la península de Yucatán considerándola acorde a la delimitación española del siglo XVI, es decir comprendiendo el espacio entre la Laguna de los Términos y la provincia prehispánica de Chetumal, omitiendo la región de Acalan que se caracterizó por una evolución histórica y documental diferenciada. Se hizo énfasis en la revisión de los documentos históricos que pudiesen dar una idea cuantitativamente significativa de la situación de los asentamientos en la península y por esa razón se optó por centrarse en el periodo que va desde el final del Postclásico, después de la caída de Mayapán, hasta el término del siglo XVI. Se utilizará la metodología de la Escuela de Topografía Antigua de Roma La Sapienza. La disciplina se basa en el estudio del paisaje arqueológico que cambia con el tiempo, y se centra en el análisis de las diferentes fases y en cómo el territorio ha evolucionado, ya sea de forma natural o por la mano del hombre. Los patrones de asentamiento, los tipos de urbanización y la subdivisión del espacio agrícola en la antigüedad, con sus desarrollos a través del tiempo son algunos de sus principales intereses (por ejemplo, Sommella., 1988; Migliorati, 2003). De hecho, la península sufrió, durante el siglo XVI, un cambio realmente impresionante: la llegada de los españoles no implicó sólo un cambio en el nivel político, sino también a nivel territorial y de asentamiento: los conquistadores trajeron con ellos sus propias categorías mentales y sus necesidades en el sentido espacial y las impusieron en sus nuevas posesiones, con enormes consecuencias para el espacio y el asentamiento. Las guerras de conquista dejaron algunas zonas despobladas, y, con la creación de un nuevo orden administrativo recto por las cuatro ciudades de la nueva fundación, nació un nuevo sistema de puntos de poder en el territorio, mientras que la congregación redistribuyó totalmente la población en el espacio. Al mismo tiempo, todos los conceptos europeos, como la idea de fronteras, la propiedad privada y el poder "territorial", se insertaron con fuerza en la cultura maya, modificándola definitivamente.Si bien, para los mayas yucatecos de la época prehispánica, el poder no era de tipo territorial, sino personal, y sólo después de la conquista adquirió en parte una acepción territorial, para efectos del presente trabajo y para facilitar la identificación de las áreas de la península, se ha optado por mantener el uso de los nombres de provincias empleados por Ralph Roys, ya que son los mismos utilizados por los conquistadores en los documentos coloniales. Este uso debe ser entendido sólo como una herramienta de conveniencia para indicar partes del territorio, y no entidades políticas con fronteras definidas.

\section{MATERIALES Y MÉTODOS}

Se ha utilizado la metodología de la Escuela de Topografía Antigua de la Universidad de Roma La Sapienza, centrada en el estudio a $360^{\circ}$ del objeto arqueológico en cuestión. En este caso, un estudio geográfico y topográfico del territorio yucateco fue seguido por un estudio histórico y documental, y con análisis de mapas antiguos y modernos, con el fin de tener una visión lo más completa posible

Trabajos paleolimnológicos recientes han descubierto variaciones climáticas en esta zona a través de los milenios. El análisis de sedimentos de algunos lagos yucatecos demostró que la vegetación y el clima se mantuvieron bastante similares a lo largo del tiempo, y que son comparables al presente, a excepción de algunos períodos más secos (Brenner et al., 2003; Brenner, Rosenmeier, Hodell \& Cortis 2002; Kennet et al. 2012:789,791; Curtis \& Hodell, 1996; Hodell, Brenner, Curtis \& Guilderson 2001; Allen \& Ricón, 2003). Esto nos permitió explotar también metadatos y estudios ambientales recientes (por ejemplo, Duch, 1988; Duch, 1991), aunque 
siempre comparandolos con las fuentes históricas, con el fin de contar con un marco geográfico del período en cuestión lo más correcto posible. Para hacer nuestro estudio más comprensible y más accesible, se construyó un SIG, a partir del cual vienen las dos imágenes en el artículo.

En la primera imagen, para alimentar el sistema de información geográfica implementado, fue utilizado como base la imagen satelital "world imagery" de los basemap de ArcGis. Sobre esta fueron colocados los poblados mencionados en los primeros documentos coloniales, como las Relaciones historico-geográficas de Yucatán y los Documentos para la historia de Yucatán, junto con otras fuentes históricas. Su ubicación fue obtenida de mapas antiguos, estudios toponímicos de imágenes satelitares y trabajos previos (Roys, 1957; Quezada, 1993a; Góngora, 2002). Tenemos que considerar que los procesos histórico-sociales que ocurrieron en el período colonial, y en particular la congregación, hayan modificado la ubicación de algunos topónimos, y que el dato de su posición en época prehispánica sea ahora compromiso y difícil de corroborar. En la segunda imagen, se ha insertado, en el mismo basemap de la primera imagen, la reconstrucción de la congregación en el curso del siglo XVI. Los datos se obtuvieron a partir de documentos históricos como las Relaciones histórico-Geográficas, trabajos de históricos de siglos pasados como Cogolludo, junto con estudios recientes como los de Sergio Quezada.

\section{DISCUSIÓN}

\section{La distribución de los asentamientos}

Yucatán tiene suelos someros y pedregosos, no muy fértiles (Bautista \& Palacio, 2005, INEGI, 1984, Duch 1991), pero el profundo conocimiento de los diferentes tipos de suelo permitió a los mayas explotarlos al máximo de sus capacidades. A partir del Preclásico, el sistema de cultivo más utilizado fue la milpa, basada en la técn- ica de "roza, tumba y quema" (Allen \& Ricón, 2003). Sin embargo, en este modo, después de que la tierra había sido utilizada por algunos años, se empobrecía y se volvía inservible: tenía que quedar sin cultivo por muchos años para que la vegetación tuviese la oportunidad de crecer y el campo pudiese ser cultivado de nuevo. Naturalmente, con un sistema agrícola de este tipo, se necesitaba una gran cantidad de tierra para sostener una familia a través de los años, y esto favoreció una tipología de asentamiento disperso: los campesinos mayas vivían esparcidos sobre el territorio, para poder aprovechar toda la tierra posible, con la única limitante de la geografía y del acceso al recurso hídrico (Carosi, 2016). Sin embargo, esta tendencia a la dispersión fue siempre unida a otra, contraria y centrípeta, que permitió la presencia de pueblos, ciudades y capitales (Farriss, 1992; Ligorred, 2013).

De acuerdo con las investigaciones arqueológicas (por ejemplo, Robles y Andrews, 2002 o Góngora, 2002), la ciudad maya no tenía límites claros: simplemente, la concentración de las estructuras iba disminuyendo al alejarse de un centro urbano, mientras que las viviendas se extendían sobre toda la plana yucateca, en un tipo de asentamiento en el que los núcleos urbanos más compactos estaban reemplazados gradualmente por estructuras de viviendas de menor complejidad dispersas en las milpas, sin una clara ruptura etre el paisaje de la ciudad y el de campo.

Incluso en el ámbito campesino, la situación no era diferente: no existía la propiedad privada o límites bien definidos entre las milpas. En la mentalidad maya, la tierra misma era una entidad dadora de vida y nutrimento y no podía ser objeto de comercio. Por esto,la mayoría de la tierra era propiedad comunal: en el momento de la siembra, cada familia elegía su propia zona para cultivarla y aquí ponía un signo para marcarla como propia y disfrutar de los frutos, sin fronteras o límites claramente definidos (Quezada, 2001; Quezada, 1993a). Por lo tanto, la totalidad del territorio se presentaba como un continuum de estructuras y 
campos, en los que, a partir de los núcleos ar- mientras que la concentración de las estructuras quitectónicos se pasaba gradualmente a la milpa, iba disminuyendo.

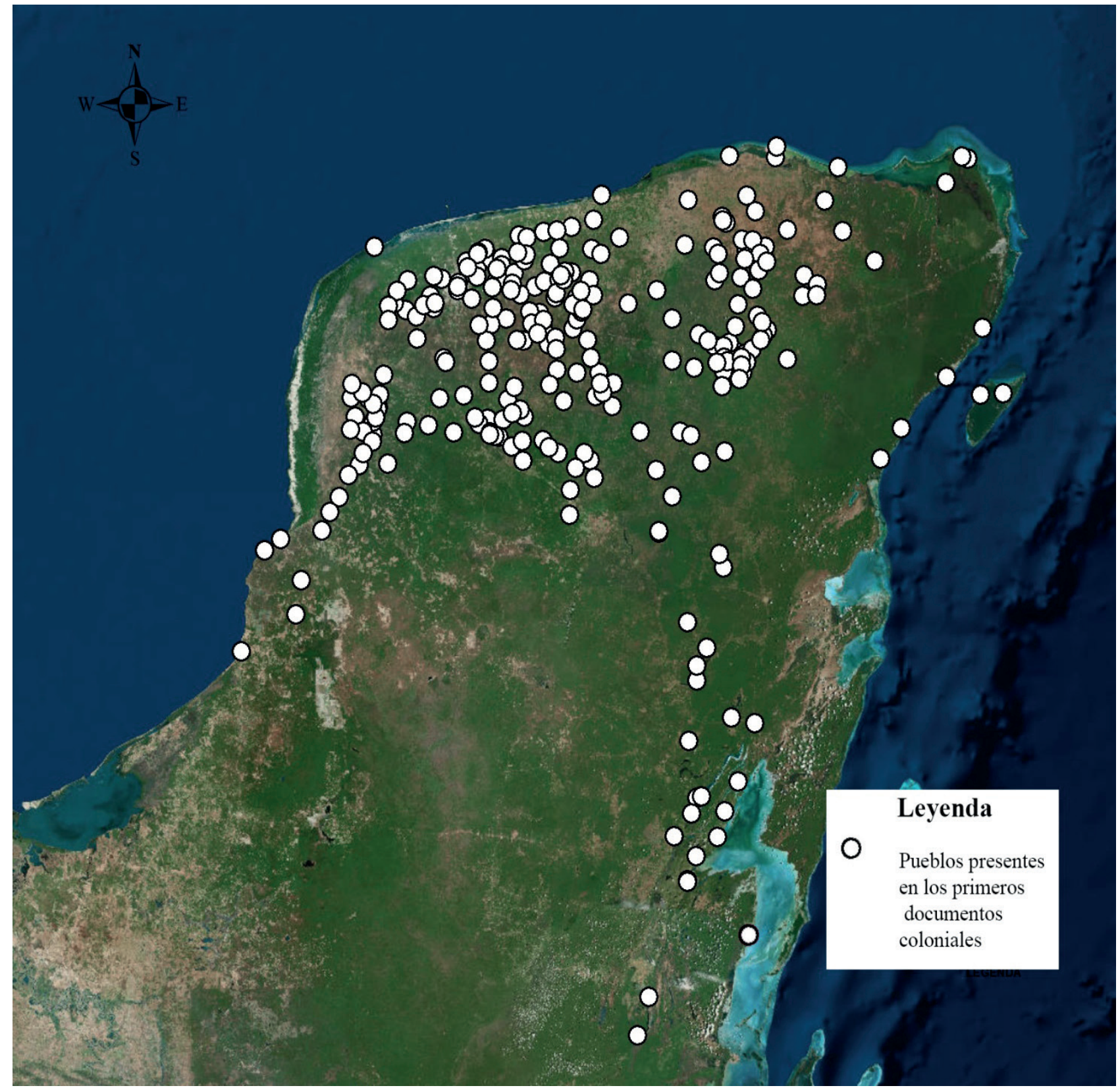

Figura 1. Disposición de los de los asentamientos coloniales de Yucatán certificados por fuentes históricas. Fuente: Elaboración propia del autor con base de ESRI.

La aparente homogeneidad geográfica yucateca esconde varios hábitats diferentes con características específicas que influenciaron la distribución de las ciudades. La imagen resultante del SIG implementado muestra claramente un patrón de asentamiento irregular, mismo que responde no solo a factores histórico-sociales, sino también medio ambientales. Como se puede ver en la imagen 1, toda la banda norte cercana a la costa estuvo deshabitada por su ambiente formado por 
ciénagas y esteros inundados durante todo el año. Este ambiente, claramente, no era ideal para la vida cotidiana. Sin embargo, el área fue explotada durante toda la historia yucateca para instalar salinas. La sal era de hecho uno de los mayores tesoros de la península de Yucatán, y siempre fue exportado a lo largo de la historia yucateca (Andrews, 1980). En Yucatán, los suelos tienden a volverse más profundos desde el norte hacia el sur y desde el oeste hacia el este; también el acuífero, que aqui constituye la única fuente de abastecimiento de agua, fluye más profundo de norte hacia el sur (Duch, 1991). Los poblados se asentaron preferentemente en puntos estratégicos: mirando el mapa (figura 1) se puede observar una concentración de pueblos cerca de la costa, al sur de la zona pantanosa. En general en esta área dominan suelos pedregosos y poco profundos, pero el agua subterránea está bien accesible, y la proximidad al mar compensa el suelo poco fértil: la posición, de hecho, dejó explotar los productos del mar, como la sal y el pescado, e insertarse en la ruta comercial Veracruz-Honduras que rodeaba a la península. Las áreas más al sur fueron también densamente pobladas, por tener suelos mediamente profundos y fertiles. Sabemos que, entre Chichén Itzá, Tizimin y Valladolid se cultivaba también el cacao, un cultivo que, debido a los suelos yucatecos someros, no podía crecer en otra parte de Yucatán (Andrews, 2014).

Muchos pueblos estaban dispuestos a lo largo de los caminos más importantes, un ejemplo muy claro es la línea de asentamientos que se puede ver en la imagen 1 a lo largo del camino prehispánico que sería llamado Camino Real MéridaCampeche (Carosi, 2016). Se trata también en este caso de puntos estratégicos: posicionar una ciudad cerca de una carretera importante permitiría un mayor y más fácil contacto con los sitios distantes, y por lo tanto facilitaría el comercio reduciendo los tempos de viaje y transporte.

Entre el distrito de Bolonchén y la sierrita de Ticul, la imagen 1 muestra un área aproximadamente triangular, la región Puuc, muy poco poblada. Estando entre dos zonas más elevadas, aquí están los suelos más profundos de la península. Esto es una ventaja para la agricultura, pero la vivienda permanente es problemática porque el acuífero fluye a gran profundidad, resultando inaccesible. Entonces, en ese momento, sólo se pusieron aqui campos para disfrutar la riqueza de la tierra (Ciudad Real, 1976), pero no asentamientos estabiles, mientras los campesinos pusieron sus poblados en el oeste del distrito de Bolonchén y en el este de la Sierrita de Ticul, donde también los suelos eran profundos y ricos, pero el acuífero resultaba alcanzable, y sus milpas de la región Puuc estaban accesibles (Carosi, 2016).

Como se puede ver, la imagen 1 muestra una fuerte despoblación de la zona de Ecab, Uaymil y Chetumal, especialmente en el interior. La zona fue objeto de la violenta expedición de Pacheco, que, de acuerdo con los historiadores, había dejado la zona prácticamente despoblada. La mayor parte de los documentos que poseemos hoy en día son siguientes a este hecho, y esto impide una buena reconstrucción de la situación anterior, pero los primeros navegantes testimonian que estas regiones estaban muy pobladas. Las pocas ciudades que ha sido posible reconstruir por las fuentes están ubicadas a lo largo de la costa. Toda esta zona está presentada en las fuentes históricas como extremadamente dinámica, dedicada al comercio: de hecho, el fácil acceso a la costa permitía insertarse en la ruta Veracruz-Honduras (Chamberlain, 1948).

\section{El sistema de los cuchcabaloob}

Con la caída de Mayapán, los linajes que la habían gobernado durante casi dos siglos la abandonaron y se diseminaron sobre el territorio yucateco estableciéndose en algunas ciudades desde las que, con el rango de halach uinic, comenzaron a gobernar de forma independiente, cada uno en su propio territorio. El número exacto de capitales y cuchcabaloob que se formaron en ese momento es desconocido, pero a la llegada de los conqui- 
stadores, un siglo más tarde, había por lo menos dieciocho centros de poder (Quezada, 2001; Okoshi \& Quezada, 2008).

De acuerdo con los estudios históricos realizados por Sergio Quezada, había tres niveles de jerarquía dentro de la estructura administrativa, constituida por cuchteelob, batabob y cuúchcabaloob. (Okoshi \& Quezada, 2008; Quezada, 1993a; Quezada, 2014a; Quezada, 2014b): la suma de varios cuchteelob conformaban el batabil, y varios bataboob estaban subjetos a un halach uinic. Similarmente a lo que pasaba con el asentamiento, también el territorio administrado por un poder político no estaba claramente demarcado. Si se desea leer el aspecto político pre-hispánico desde un punto de vista territorial, se tendría una visión muy caótica, en la que el territorio sujeto a un oficial estaba territorialmente discontinuo y mezclado con otras áreas sujetas a otros funcionarios, a todos los niveles de poder.

Por ejemplo, el territorio de un batabil no se presentaba como algo unitario y bien definido: los cuchteeloob no constituían una unidad territorial compacta, sino a menudo estaban esparcidos, sin límites claramente definidos, y el batab residía en uno de ellos (Quezada1993b; Quezada 1993a). El cuúchcabal representaba el nivel más alto de la estructura. La mayoría de ellos aparecían relativamente unificados en términos de territorio, pero esto no fue el caso de todos. Un ejemplo típico es la situación de los Cupules, con cuatro capitales diferentes, donde los cahob pertenecientes al poder de uno o de un otro halach uinic estaban diseminados sobre la comarca y las soberanías de las capitales sobre ésta se entrelazaban y se cruzaban sobre el territorio (Okoshi \& Quezada, 2008). Los batabob podían optar por quedarse vinculados políticamente a un señor a través de los lazos de sangre, ser independientes o ser vasallos de un halach uinic de diferente linaje. Por lo tanto, el halach uinic reinaba hasta donde estaba reconocido como señor. En la mentalidad maya existía un centro urbano desde que el poder se ampliaba sobre un conjunto de ciuda- des y sitios que no necesariamente tenían continuidad territorial, sino a menudo se mezclaban con grupos dependientes de poderes distintos. En esta manera de ver las cosas, no existían límites físicos netos y tenía significado sólo el alcance de poder personal (Okoshi \& Quezada, 2008).

\section{La organización después de la conquista}

Con la llegada de los conquistadores, en 1527 , empezó el período de conquista militar que se mantuvo con altibajos hasta 1547. Las grandes trasformaciones territoriales comenzaron poco después, cuando se procedió a reorganizar a las zonas conquistadas.

Todo el territorio peninsular se dividió en jurisdicciones administradas por las cuatro ciudades recién fundadas: la capital estuvo asentada en Mérida, con un distrito que incluía las áreas de Hocabá, Chakán, Ceh Pech, Sotuta y Maní. Valladolid se ocupó de las zonas de Cupul, Tazes, Chikinchel, Ecab, Cozumel y Cochuha; San Francisco de Campeche tenía, entre otros, los cacicazgos de Ah Canul, Champotón y Canpech, mientras que a Salamanca de Bacalar pertenecían Uaymil y Chetumal (Chamberlain, 1948; Scholes, Menéndez, Rubio Mané, \& Adams, 1938). El poder de toda la región estuvo en las manos de un único funcionario: el alcalde mayor (Quezada, 1993b).

Inicialmente, los españoles confirmaron al poder todos los señores locales que aceptaron la supremacía de la corona de Castilla, perpetuando el sistema político maya. Sin embargo, con sólo la llegada de los españoles, arribaron en Yucatán las categorías del pensamiento hispánico, que a menudo se superpusieron a términos de lengua maya, cambiando su naturaleza en el profundo. Por lo tanto, el batabil se convirtió en "el señorío", el cuchteel fue "barrio o parcialidad", el lugar de residencia del halach uinic la "cabecera" (Quezada, 1993b; Restall, 1997), y en este modo la misma idea del poder empezó a cambiar, conformándose acorde al pensamiento 
europeo. Entró el concepto de propiedad privada, y las ciudades también comenzaron a comprar terrenos, mientras la tierra se convirtió en un bien comercializable (Roys, 1972).

Al mismo tiempo, también cambió la concepción misma de la política y se impuso una mentalidad de estilo occidental en la que el poder está imprescindiblemente vinculado a un territorio bien definido. Ya durante los primeros años despues de la conquista, los señores locales tuvieron que adaptarse a este cambio de perspectiva y muchos de ellos redefinieron su propio territorio clarificando los límites, donde pusieron mojones y cruces (Okoshi \& Quezada, 2008). En 1545, se definieron los límites de la región de Sotuta. Nachi Cocom en persona fijó los límites de su comarca (Roys, 1972). El 15 de agosto de 1557, el halach uinic Don Francisco de Montejo Xiu se reunió en Maní con los gobernadores de Oxkutzcab, Tekax, Ticul, Muna, Mama y Tekit para definir los límites territoriales de cada uno. Después fueron plantadas las cruces en los campos de la ciudad, con el fin de marcar visualmente los límites en el terreno (Roys, 1957; Roys, 1972). De todos modos, la situación territorial se mantuvo ambigua durante mucho tiempo e incluso en los siglos XVII y XVIII hay atestiguamientos de propiedad de tierras en común por la mayoría de las ciudades.

La imposición de una unidad de poder central, asentada en Mérida, rompió las viejas formas políticas propias de los cuúchcabalob y el sistema de la encomienda dividió las regiones en distintas repúblicas de indios transformando las comunidades en unidades administrativas absolutamente independientes. El mismo término halach uinic perdió su significado quedando sólo como título honorífico y los halach uinicob se volvieron gobernadores sólo de los pueblos que un tiempo habían sido capitales de cuuchcabaloob. Esto llevó a crear una situación de gran fragmentación en Yucatán (Farriss, 1992; Restall, 1997), con cada pueblo distinto en su derecho político y fiscal, como una entidad independiente, llegando finalmente a la completa desintegración del antiguo sistema de organización territorial.

Junto a esto, sin duda, el cambio mas importante a nivel de asentamiento, está vinculado a la acción de los misioneros.

Una población dispersa sobre el territorio como hemos visto, en un area tan extensa, habría hecho muy difícil el trabajo de conversión realizado por los frailes, ya pocos en número, y alargado el momento de la conversión: llegar a todas las almas que habitaban esos lugares se volvía prácticamente imposible. Para resolver este problema, se optó por modificar el mismo modo de asentamiento en Yucatán (Farriss, 1992).

Parece que ya inmediatamente después de su llegada, los franciscanos se dedicaron a la congregación de la población en sitios específicos, pero no fue hasta 1552, y con el apoyo del oidor Tomás López, que el proyecto alcanzaría su plena madurez, continuando a lo largo de la segunda mitad del siglo (Farriss, 1992). Desde 1552, los habitantes de ciudades, aldeas y pequeños grupos de casas estuvieron todos reunidos en sitios seleccionados para poder garantizar un buen trabajo de evangelización, de preferencia en zonas de fácil administración y accesibilidad, así que fuese fácil "predicar, catequizar y enseñar" (Cogolludo, 1957). Pueblos enteros cambiaron de asiento para simplificar el trabajo de los frailes.

Se puede tener una idea de las dimensiones que alcanzó esta operación mediante la observación de la imagen 2. Como se puede ver, regiones enteras, como Ah Canul y Maní, estuvieron prácticamente despobladas, mientras que toda la población se concentraba ahora en la cabecera. Por el caso del Ah Canul, en 1549 había allá diez pueblos, y entre 1552 y 1582 estaban desaparecidos, todos reunidos en la capital provincial Calkini (Scholes et al., 1938; Cogolludo, 1957; Quezada, 1993a). La imagen también muestra una fuerte despoblación a lo largo del tramo septentrional 
de la costa este, mientras que los residentes de varios sitios costeros, entre ellos el mismo Conil, fueron trasladados en puntos no determinados (Landa, 1941).

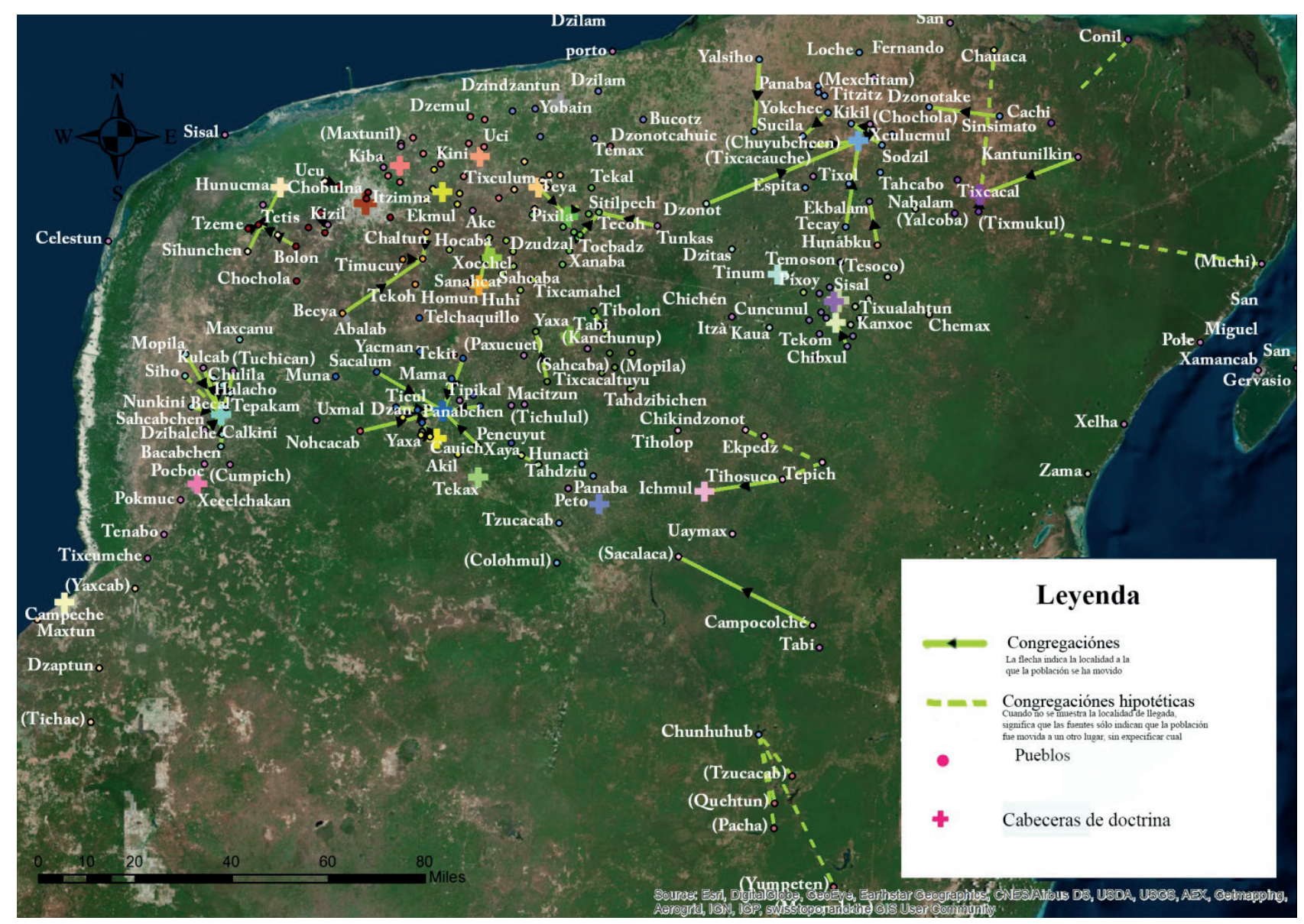

Figura 2. Congregaciónes . Fuente: Elaboración propia del autor. Imagen de base de ArcGis

La elección del lugar donde reunir estas grandes cantidades de personas, a menudo representado por una gran ciudad existente, no fue casual: era necesario tener en cuenta donde se ubicaba el convento más cercano, pues era allí donde los frailes vivían y allí dónde los nativos tendrían que reunirse para muchas actividades. Era también importante que estos puntos fuesen bien accesibles, en zonas planas (Quezada, 1993b). Como se puede ver en la imagen 2 , se eligieron a menudo lugares importantes, puestos en los cruces de carreteras, como Hunucmá, Acanceh y Homún, o cabeceras de la doctrina como Homún e Izamal. Puntos de atracción especial fueron las ciudades situadas a lo largo del Camino Real Valladolid-
Rio Lagartos, como Kinkil y Tizimin. Al mismo tiempo, las ciudades elegidas para congregar a la población fueron modificadas en su aspecto y se les impuso el patrón de la red viaria de tipo ortogonal típico de la tradición occidental, con su plaza, iglesia, casa real y posada. Además, los pueblos tendrían que definir de forma clara y oportuna sus límites territoriales. No siempre los sitios elegidos para reunir a los nativos eran adecuados: un buen ejemplo es el caso de Tecoh, Ah Kin Chel, situado en un lugar poco saludable y flanqueado por una charca de agua infectada. Por la insalubridad de la zona, la ciudad había sido abandonada, pero con la reducción, muchos indígenos fueron reunidos allí por su cercanía al 
convento de Izamal, y muchos murieron (De La Garza et al., 1983).

A veces los cahob reunidos en un mismo sitio pronto se convirtieron en una sola unidad con la ciudad que los acogió, convirtiéndose en barrios, siendo que el recuerdo de su autonomía anterior se perdió por completo. Por el contrario, otros pueblos congregados, sobre todo si habían disfrutado de un estatus más o menos comparable con el del poblado con el que se fusionaron, mantuvieron su propia identidad, incluso décadas después de la Reducción, de manera que no es raro encontrar, en textos coloniales, la documentación de fiestas que no incluyen a todo el poblado, sino solo a una parcialidad. También es posible encontrar afirmaciones de independencia política respecto al consejo ciudadano o al batab, esto aun estando "en el mismo asiento" de otra ciudad. A veces los límites territoriales de poblaciones congregadas permanecieron diferenciadas, ya que las residencias se concentraron en unas áreas distintas, incluso dentro de las fronteras del pueblo donde se congregaron, compartiendo con él, en última instancia, sólo la iglesia y la plaza (Scholes et al., 1938; Farriss, 1992). Claramente, la reducción creó problemas no sólo locales sino también políticos: sucedió que dos caciques diferentes se reuniesen en el mismo sitio (Quezada, 1997).

Para los franciscanos, la congregación fue un trabajo largo, que coincidió con gran parte de la segunda mitad del siglo XVI. Ya en los años sesenta, sin embargo, habían logrado congregar gran parte del área noroeste de la península (Quezada, 1993b).

El proceso de las congregaciones no debe ser considerado como algo conseguido de forma definitiva o de un solo golpe, sino que más bien como algo fluido en un proceso de transformación continua. Es fácil encontrar ejemplos de pueblos a los que se permitió regresar a su posición anterior (Quezada, 1993a; Scholes et al., 1938) o pueblos traslados de una ciudad a otra a través del tiempo (Roys, 1957; Scholes et al., 1938): Uitzil, en el mismo asiento de Chamalte en 1582, estaba en Dzudzal en 1688, (Roys, 1957; Scholes et al., 1938). De hecho, parece que entre 1565 y 1582 alrededor del $40 \%$ de los pueblos congregados pudieron regresar a su posición original (Restall, 1997). Un claro ejemplo se encuentra en la ciudad de Maní, allí entre 1547 y 1548 los franciscanos habían reunido doce ciudades: más tarde, al fundarse en Tekax un convento, a los habitantes de Pencuyut se les permitió regresar a su probable asiento original. Posteriormente, cuando Oxkutzcab tuvo su convento, Yaxá y Tikunché mudaron su asiento y fueron congregadas en esta segunda ciudad, mientras Pustunich regresó a lo que fue probablemente su posición original, no lejos de la nueva cabecera de doctrina. Por último, en 1582 ni Mama, Tekit o Teabo estaban más en su antigua cabecera mientras que Panabchén, Sacalum y Dzan estaban quizás de nuevo en su ubicación original, sin dejar de ser dependientes del convento de Maní: en el pueblo de Maní sólo quedaba Ticul (Quezada, 1993a).

Guerra, enfermedades y fuga de nativos hacia otros lugares se sumaron para configurar una terrible crisis demográfica que, a lo largo del siglo XVI, empeoró más y más, con profundos efectos en la situación del asentamiento, dejando algunas ciudades y también regiones casi despobladas. Estas, junto con las congregaciones realizadas por los frailes a partir de 1552, fueron las causas principales que ocasionaron una enorme alteración en la disposición de la población sobre el territorio.

El primer documento de tasación de Yucatán, conservado ahora en el Archivo General de Indias, muestra la situación en 1549, unos años antes del real comienzo de la congregación: de hecho, enumera unos pueblos yucatecos, acompañados por el importe del impuesto adeudado por cada una. No aparecen los pueblos de las regiones de Hocabá, Canpech, Champotón, Uaymil y Chetumal. El documento certifica la presencia de 57.644 tributarios para 178 pueblos mencionados (Cook 
\& Borah, 1974). En Canpech, a cuatro leguas del pueblo de indios del mismo nombre (Ciudad Real, 1976), fue fundada la villa española de San Francisco en 1541, uno de los cuatro puntos de la península donde se concentró la población española después de la Gran Revuelta, mientras el distrito de San Román fue uno de los lugares para los mexicanos auxiliares que habían ayudado a los conquistadores (Perry \& Perry, 2002). De ser una gran ciudad de 3.000 casas, en 1549, Canpech sólo tenía 630 tributarios. En la región de Chikinchel, una vez próspera y dedicada al comercio, sólo el 28\% de los cahob prehispánicos permanecía habitado (Kepecs, 1997). La población había disminuido rápidamente, y se reunía en las ciudades de Río Lagartos, Emal, Loche, Chauaca, Aké y Dzonotake: en Sinsinbahtoc, una vez habitada por 600 hombres, vivían ahora solo noventa tributarios (Roys, 1957; De La Garza, Izquierdo, Del Carmen Leòn, \& Figueroa, 1983) e incluso en Chauaca, la instalación de una ciudad española en la orilla occidental del lago, abandonada después de pocos años, había sido increíblemente dañina: de ser una ciudad grande y populosa, se transformó en una ciudad con sólo 200 tributarios. La provincia de Cochuha había sufrido también pérdidas considerables en los años cuarenta, y muchos habían huido a las islas de Bahía de la Ascensión (Roys 1957:136) y regiones vecinas. En la región de Ecab, Xamanhá ya estaba abandonada (Roys, 1957) y P'olé tenía ahora sólo 17 tributarios (Cook \& Borah, 1974). Está claro que ya había empezado el proceso de despoblamiento que décadas después mostraría todas sus consecuencias.

La situación se agravó a lo largo del siglo. Las Relaciones histórico-geográficas proporcionan un marco valioso para la comprensión de la situación en los años setenta del siglo XVI. En Chikinchel es evidente la devastación causada por la congregación: la población de Sinsinbahtoc había sido trasladada a otro lugar y en el sitio antiguo sólo quedaban ocho tributarios (De La Garza et al., 1983). En el asiento de Chauaca en 1579 sólo había 20 familias (De La Garza et al.,
1983). Loché, que en 1528 era "la ciudad más grande que los españoles habían visto", en 1588 sólo era un "poblecito pequeño" (Ciudad Real, 1976).

En el área regida por los Cupules, en comparación con 1549, la situación era la siguiente: en Chocholá la población estaba reducida a la mitad (Gates, 1937) y en Pixoy quedaba sólo un tercio (De La Garza et al., 1983). Un tiempo poderosa, Chichén Itzá se dirigía hacia la decadencia. En 1588 ya no estaba habitada, sino que sólo se utilizaba como rancho para la cría de ganado (Ciudad Real, 1976).

En Ecab la despoblación es clara: Isla Mujeres estaba deshabitada (De La Garza et al., 1983); las salinas ya no se utilizaban (Roys, 1957; De La Garza et al., 1983) y Tzamá estaba reducida a un pueblo con menos de 50 tributarios (De La Garza et al., 1983). Sobre la región de Cochuha sabemos que la construcción del convento, en 1576, generó en Ichmul un fuerte crecimiento de la población. Aparte de Ichmul, otras ciudades de la región sufrieron el mismo proceso de descenso demográfico (Roys, 1957; De La Garza et al., 1983). También son evidentes los signos de la acción de reducción en otros lugares de la zona, pues muchos pueblos fueron abandonados y sus habitantes fueron reunidos en las principales ciudades como Tepich.

Por su parte, de la pasada grandeza de Uaymil y Chetumal ahora quedaba poco: la dramática respuesta española a la Gran Revuelta Maya había diezmado a gran parte de la población. Los pocos pueblos supervivientes se mantuvieron a lo largo de los caminos de la ciudad, tal fue el caso de Xoca, Pacha, Tzucacab, Yuyumpeten; o a lo largo de las costas de la Bahía de Chetumal y del mar Caribe, o de los rios de Chetumal.

En contraste con la tendencia general de disminución de la población, en algunos lugares la congregación dio lugar a un resultado opuesto, ofreciendo a algunas ciudades una importancia 
que nunca habían tenido en tiempos prehispánicos. Trastornos políticos importantes tuvieron lugar en la región llamada Tazes por la congregación: prácticamente todos los pueblos de la zona se habían reunido en Chancenote dejando vacía la región y incluso a Ichmul creció el número de habitantes, debido a la congregación (Roys, 1957; De La Garza et al., 1983). Izamal, que a pesar de ser un gran punto de peregrinación, antes de la llegada española era un pequeño pueblo, adquirió un nuevo prestigio: aquí se llevó a cabo la construcción de uno de los primeros y más importantes conventos de toda la península de Yucatán, y aquí fueron congregados los habitantes de dos pueblos, logrando obtener de esta manera un prestigio a nivel territorial que en época pre-hispánica no tenía (Cogolludo, 1957). Lo mismo pasó a Tizimín: punto obligatorio de paso en la ruta que conectaba Valladolid con la costa, fue muy valorado en esta época. Se reunieron aquí tres pueblos y en 1563 se convirtió en cabecera de doctrina (Cogolludo, 1957; Roys, 1957), y en el siglo XVII dio nombre a una amplia región que incluía la zona noreste de la península.

Por supuesto, estos datos no son interesantes sólo desde un punto de vista demográfico, sino también influyeron fuertemente la situación del asentamiento. En muchissimas ciudades prehispánicas, una vez florecientes, se redujo la población en el espacio de cincuenta años, y regiones enteras fueron prácticamente despobladas, mientras que la población, que vivía una vez en todo el inmenso territorio peninsular, ahora estaba reunida en pocas ciudades para cada provincia, lo que llevó a la desintegración completa del sistema de asentamiento preexistente y a la afirmación de un nuevo orden, no sólo político, sino también territorial.

\section{CONCLUSIONES}

En la última parte del Postclásico, la población maya de Yucatán estaba dispersa por toda la península. La técnica de la milpa había llevado a este tipo de asentamiento, ya que, para sostener a una familia en el tiempo, se requiería una gran cantidad de tierra. Obviamente, el elemento geográfico impidió que la población podría repartirse uniformemente en todo el territorio. Por el contrario, como se muestra en la imagen 1, en Yucatán la urbanización siguió a las características topográficas y los sitios se pusieron en las zonas más ventajosas, cerca del mar, donde el acuífero estaba de fácil acceso o donde los suelos eran más fértiles. El asentamiento consistía en ciudades y pueblos de distintos tamaños esparcidos por las llanuras, sin límites precisos. Eran núcleos, aglomerados de estructuras más o menos grandes y más o menos complejos, con una concentración que disminuía alejandose del centro hasta las milpas, en una situación general de continuidad, sin rupturas abruptas. Políticamente, estaba dividida en cuuchcabalob bajo la protección y el dominio de diferentes $h a$ lach uinicob. Su poder, de tipo personal, no tenía límites territoriales claros y llegaba hasta donde la población estaba dispuesta a reconocerlos.

Con la llegada de los españoles, las cosas cambiaron: Llegaron los conceptos europeos como la propiedad privada, la misma idea del poder cambió y, de personal, se volvió territorial, mientras que algunos señores mayas definieron los territorios de sus comarcas a través de la colocación de cruces y mojones y por medio de la creación de mapas especiales; la tierra fue ahora un bien vendible y los poblados comenzaron a comprar terrenos. La congregación revisó completamente el diseño de la presencia de la gente en el territorio: aldeas y grupos de casas dejaron de existir, y pueblos enteros fueron reducidos en otros, en un cambio no sólo de los fulcros sobre el territorio, pero de la misma manera de habitar el territorio. Además, una profunda crisis demográfica devastó la península, y ciudades en un tiempo poderosas se convirtieron en pequeños pueblos, mientras, por las reducciónes, otras ciudades como Tizimín e Ichmul, adquirieron un prestigio del que nunca habían gozado en época prehispánica. 


\section{REFERENCIAS BIBLIOGRÁFICAS}

Allen M.F. \& Rincón E. (2003). The Changing global environment and the lowland Maya: Past Patterns and current dynamics. En S. L. Fedick, M. F. Allen, J. J. Jiménez-Osornio, A. Gómez Pompa (Ed.). The lowland Maya area: Three millennia at the human. Wildland interface (pp. 15-30). New York: Haworth Press.

Andrews A. P. (2014). Organización política, económica y commercial. En S. Quezada (Ed). Historia general de Yucatán (pp.375385). Mérida, Yucatán, México: Universidad Autónoma de Yucatán.

Andrews A. P. (1980). Salt-making, Merchants and Markets: the Role of a Critical Resource in the Development of Maya Civilization Tucson: University of Arizona.

Bautista F. \& Palacio G. (2005). Caracterización y manejo de los suelos de la península de Yucatán. Implicaciones agropecuarias, forestales y ambientales. Campeche. México: INE.

Brenner, M., Rosenmeier, M. F., Hodell, D. A., \& Cortis J. H. (2002). Paleolimnology of the Maya Lowlands. Ancient Mesoamerica, 13 (1), 141-157.

Brenner, M., Hodell, D. A., Curtis, J. H., Rosenmeier, M. F., Anselmetti, F. S. \& Aritzegui, D. (2003). Paleolimological Approaches for Inferring Past Climate Change in the Maya Region: Recent Advances and Methodological Limitations en A. Gómez-Pompa, M.F. Allen, S.L. Fedick \& J.J. Jiménez-Osornio (Ed). The Lowland Maya area: three Millennia of the Human-Wildland Interface (pp. 45-75). New York, The Haworth Press: Binghamton,

Carosi G. (2016). Conformazione territoriale e popolamento: lo Yucatan all'inizio del XVI secolo. Thule, rivista italiana di studi americanistici, EN PRENSA.

Chamberlain, R.S. (1948). Conquest and colonization of Yucatan. Washington, D.C.: Carnegie Institution of Washington.

Ciudad Real A. (1976). Tratado curioso y doctor de las grandezas de la Nueva España: relación breve y verdadera de algunas cosas de las mu- chas que sucedieron al padre fray Alonso Ponce en las provincias de la Nueva España siendo comisario general de aquellas partes. México, D.F.: Universidad Nacional Autónoma de México. Instituto de Investigaciones Históricas. Cogolludo, D. L. (1957). Historia de Yucatan. Mexico: Editorial academia literaria

Cook, S. F. \& Borah, W. (1974). Essays in Population History: Mexico and the Caribbean. Berkeley and Los Angeles: University of California Press.

Curtis, J. H \& Hodell, D. A. (1996). Climate variability in the Yucatán península (Mexico) during the past 3500 years, and implications for maya cultural evolution. Quaternary Research, 46 (1), 37-47.

De La Garza, M., Izquierdo, A., Del CarmenLeòn, M., \& Figueroa, T. (1983). Relaciones histórico-geográficas de la gobernación de Yucatán: Mérida, Valladolid y Tabasco. México: Universidad Nacional Autónoma de México.

Duch, G. J. (1988). La conformación territorial del estado de Yucatán: los componentes del medio fisico. México: Universidad Autónoma Chapingo Centro Regional de la Peninsula de Yucatán.

Duch, G. J. (1991). Fisiografia del estado de Yucatán: su relación con la agricultura. México: Universidad Autónoma Chapingo.

Farriss, N. M. (1992). Maya society under colonial rule, the collective enterprise of survival. Pinceton, New Jersey: Princeton University Press.

Gates, W. (1937). Yucatan before and after the conquest. Baltimore: The Maya Society.

Góngora-Salas, A. (2002). Prospección Arqueológica en la esquina Noróeste de Yucatán. Los Investigadores de la cultura maya, 10 (2), 287-294.

Hodell, D. A., Brenner, M., Curtis, J. H. \& Guilderson, T. (2001). Solar forcing of drought frequency in the maya lowland. Science, 292 (5520), 37-47.

INEGI, (1984) Carta de los suelos 1:1000000. Recuperado de: http://www.inegi.org. $m x / g e o /$ contenidos/recnat/edafologia/default.aspx. 
Kennet, D.J., Breitenbach S. F. M., Aquino V. V., Asmerom Y., Awe J., Baldini J.U.L., Bartlein P., Culleton B. J., Ebert C., Jazwa C., Macri M. J., Marwan N., Polyak V., Prufer K. M., Ridley H. E., Sodemann H., Winterhalder ${ }^{\text {B. }}$ \& Haug G. H. (2012). Development and disintegrtion of maya political systems in response to climate change. Science, 338 (6108), 788-791.

Kepecs, S. (1997). Native Yucatán and spanish influence: the archaeology and history of Chikinchel. Journal of Archaeological Method and Theory, 4 (3), 307-330.

Landa, D. (1941). Relación de las cosas de Yucatán. Cambridge (MS) : The Museum.

Ligorred, J. (2013). La descentralización de la gestión del patrimonio arqueológico en los pueblos vivos de Yucatán (México). Indicadores de participación y coordinación de los diferentes agentes públicos y sociales (México). Jangwa Pana, 12, (66- 85)

Migliorati, L. (2003) Formazione, struttura e adeguamento delle città dall'età arcaica all'impero, En P. Sommella (cur). Atlante del Lazio antico (pp.58-81). Roma: Ist. Nazionale di Studi Romani, 58-81.

Okoshi T. \& Quezada S. (2008). Vivir con Fronteras. Espacios Mayas Peninsulares del Siglo XVI. En R. Liendo Stuardo (cur). El territorio maya. Memoria de la quinta mesa redonda de Palenque (pp.137-149). México D. F.: Instituto Nacional de Antropología e Historia.

Perry, R. D. \& Perry, R. W. (2002). Maya missions. Santa Barbara, California: Espadaña Press.

Quezada, S. (2014a). Organización política maya 1450-1550. En S. Quezada (Ed). Historia general de Yucatán (pp.389-398). Mérida, Yucatán, México: Universidad Autónoma de Yucatán.
Quezada S. (2014b). Maya lords and lordship: the formation of colonial society in Yucatán, 1350-1600. U.S.A.: University of Oklahoma Press

Quezada, S. (2001). Tributos, limonsas, y mantas en Yucatán, siglo XVI. Ancient Mesoamerica, 12 (2), 73-78

Quezada, S. (1997). Los pies de la república. Los mayas peninsulares. México: Centro de Investigaciones y Estudios Superiores en Antropología Social/Instituto Nacional Indigenista.

Quezada, S. (1993a). Pueblos y caciques yucatecos. México: El Colegio de México, Centro de Estudios Históricos.

Quezada, S. (1993b). Espacialidad indígena y poder colonial en Yucatan (Siglo XVI). En Perspectivas antropologicas en el mundo maya (pp. 419-431). Madrid: Sociedad Española de Estudios Mayas.

Restall, M. (1997). The maya world. Yucatec culture and society. Stanford, Calif.: Stanford University Press.

Robles Castellanos, F \& Andrews A. P. (2002) Proyecto Costa Maya. Mérida: Centro INAH Yucatán.

Roys, R. (1972). The titles of Ebtun. Washington D.C.: Carniege Institute of Washington

Roys, R. (1957). Political geography of the Yucatán maya Washington D.C.: Carnegie Institution of Washington.

Scholes, F., Menéndez, C., Rubio Mané, J., \& Adams, E. (1938). Documentos para la historia de Yucatan. La iglesia en Yucatan. Mérida, Yucatan: Compañia Tipográfica Yucateca.

Sommella P. (1988). Italia antica: l'urbanistica romana Roma: Jouvence. 